\title{
Use of the Collaborative Wall to Improve the Teaching-Learning Conditions in the Bachelor of Visual Arts
}

\author{
Ricardo-Adán Salas-Rueda \\ Institute of Applied Sciences and Technology, National Autonomous University of Mexico, Mexico \\ ORCID: 0000-0002-4188-4610 \\ Jesús Ramírez-Ortega \\ Institute of Applied Sciences and Technology, National Autonomous University of Mexico, Mexico \\ ORCID: 0000-0002-4538-9203 \\ Ana-Libia Eslava-Cervantes \\ Institute of Applied Sciences and Technology, National Autonomous University of Mexico, Mexico \\ ORCID: 0000-0002-7420-3412
}

Received: 25 Jul 2020

Accepted: 4 Sep 2020

\begin{abstract}
This mixed research analyzes the use of the Collaborative Wall to improve the teaching-learning conditions in the Bachelor of Visual Arts considering data science and machine learning (linear regression). The sample is made up of 46 students who took the Geometric Representation Systems course at the National Autonomous University of Mexico (UNAM) during the 2019 school year. The Collaborative Wall is a web application that facilitates the organization and dissemination of ideas through the use of images and text. In the classroom, the students formed teams and used mobile devices to access this web application. The results of machine learning indicate that the organization of ideas in the Collaborative Wall positively influences the participation of students, motivation and learning process. Data science identifies 3 predictive models about the use of this web application in the educational field. Also, the Collaborative Wall facilitates the learning process in the classroom through the comparison and discussion of information. Finally, technological advances allow organizing creative activities that favor the active role of students.
\end{abstract}

Keywords: collaborative wall, bachelor, technology, learning, data science, teaching

\section{INTRODUCTION}

Technological advances are causing the creation of new school activities inside and outside the classroom (Costantino, 2018; Mannathoko \& Mamvuto, 2018; Pavlou, 2020). As a result, teachers use technological tools, educational platforms and web applications to facilitate the participation of students at any time (Marshalsey \& Sclater, 2019; Tadayonifar \& Entezari, 2020; Wilks, Cutcher, \& Wilks, 2015).

During the 21st century, teachers are transforming the educational context with the support of technology (Salas-Rueda, 2020; Wargo, 2020; Wet, 2017). These changes are causing that students acquire a leading role during the learning process (Gonzalez et al., 2020; Kite et al., 2020; Strycker, 2020).

Today, the roles of students and teachers are changing due to the emergence of new technological tools (Gopalan, Fentem, \& Rever, 2020; Kerr \& Lawson, 2020; Marshalsey \& Sclater, 2019). Therefore, students 
have the possibility to consult the information, use the educational platforms and review the course contents from anywhere (Brown \& Fridman, 2020; Chen et al., 2020; Rathner \& Schier, 2020).

Information and Communication Technology (ICT) has improved the teaching-learning conditions in the Faculties of Arts and Design through the use of mobile devices (Souleles et al., 2017), Learning Management System (Strycker, 2020), reality augmented (Kerr \& Lawson, 2020), technology applications (Brown \& Fridman, 2020; Marshalsey \& Sclater, 2019) and social networks (Marshalsey \& Sclater, 2019).

This mixed research proposes the use of the Collaborative Wall to improve the teaching-learning conditions in the Bachelor of Visual Arts. The Collaborative Wall is a web application that facilitates the organization and dissemination of ideas through the use of images and text. Therefore, the research questions are:

- What is the impact of the Collaborative Wall in the participation of the students, motivation and learning process?

- What are the predictive models about the use of the Collaborative Wall in the educational field considering the characteristics of the students?

- What is the students' perception about the use of the Collaborative Wall in the Geometric Representation Systems course?

\section{USE OF TECHNOLOGY IN THE FACULTIES OF ARTS AND DESIGN}

Today, educational institutions are using pedagogical models and technology to transform the teachinglearning process in the Faculties of Arts and Design (Costantino, 2018; Kerr \& Lawson, 2020). For example, the use of Blended Learning (BL) and Augmented Reality (AR) allowed the construction of new educational spaces that facilitate the teaching-learning process in the field of Design (Kerr \& Lawson, 2020). In particular, the Master of Time application facilitated the active participation of the students inside and outside the classroom, improved the academic performance about the issues of earth architecture and increased the motivation (Kerr \& Lawson, 2020).

At the College of Arts and Design, the incorporation of technology caused that students actively participate inside and outside the classroom (Souleles et al., 2017). In particular, the use of iPads facilitated the consultation of information and allowed the access to educational platforms at any time (Souleles et al., 2017). Furthermore, the teachers of the Faculty of Arts and Design organized various student-centered activities such as discussion forums through these mobile devices (Souleles et al., 2017).

In the Design course, the GFV application facilitated the collaborative work and developed the skills of the students (Brown \& Fridman, 2020). Even this application favored the critical thinking and realization of the discussion forums during the face-to-face sessions (Brown \& Fridman, 2020). Technological advances are causing substantial changes in the Faculty of Arts and Design (Costantino, 2018). For example, Science, Technology, Engineering, Arts and Mathematics (STEAM) are improving the teaching-learning conditions through the active participation of the students before, during and after the face-to-face sessions (Costantino, 2018).

In the Visual Arts course, the use of technology facilitated the assimilation of knowledge and development of skills (Wilks, Cutcher, \& Wilks, 2015). In fact, the use of web applications and pedagogical models transformed the teaching-learning process on the Visual Arts (Wilks, Cutcher, \& Wilks, 2015). In the field of Arts and Design, teachers use the Learning Management System (LMS) such as Moodle and Blackboard to facilitate the assimilation of knowledge and develop the skills of the students (Strycker, 2020). Likewise, the incorporation of LMS in the school activities allows acquiring the knowledge at home in order to carry out the collaborative activities during the face-to-face sessions (Strycker, 2020).

In the Contemporary Communication Design course, the students acquired a leading role during the realization of the school activities through the use of social media and technology applications (Marshalsey \& Sclater, 2019). In particular, Snapchat facilitated the communication and interaction between the 

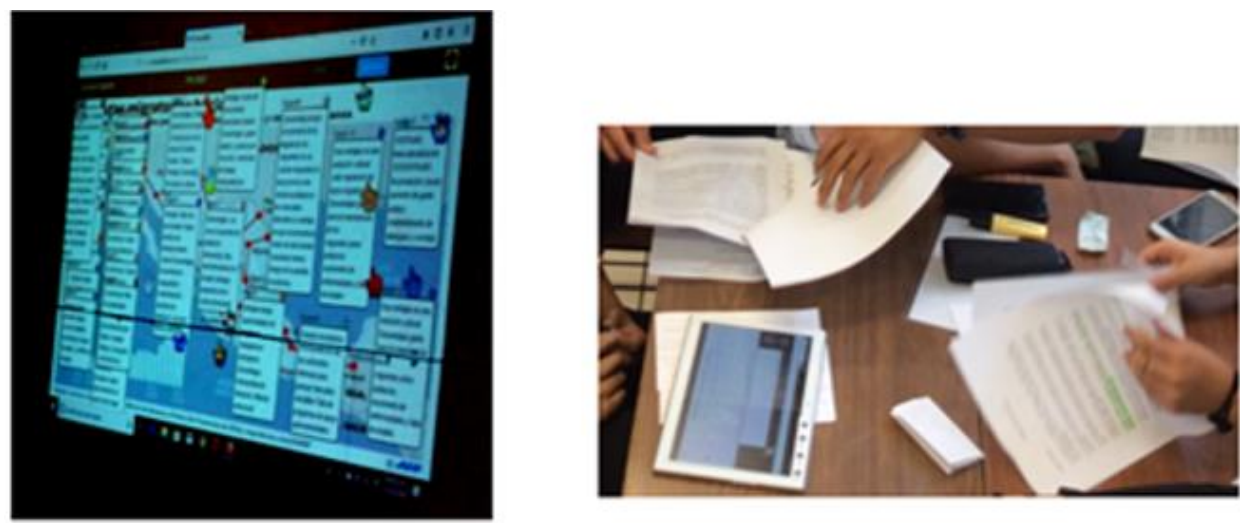

Figure 1. Collaborative Wall

participants of the educational process (Marshalsey \& Sclater, 2019). Furthermore, the GoPro application facilitated the active role of students through the creation of videos (Marshalsey \& Sclater, 2019).

Technology is transforming the school activities, functions and attitudes of students and teachers at the Faculties of Arts and Design (Marshalsey \& Sclater, 2019; Strycker, 2020). Consequently, institutions have the opportunity to build new educational spaces with the support of digital tools (Brown \& Fridman, 2020; Kerr \& Lawson, 2020; Salas-Rueda, Salas-Rueda, \& Salas-Rueda, 2020).

\section{METHOD}

This mixed research analyzes the use of the Collaborative Wall to improve the teaching-learning conditions in the Bachelor of Visual Arts considering data science and machine learning (linear regression). The particular objectives are (1) analyze the impact of the Collaborative Wall in the participation of the students, motivation and learning process, (2) establish the predictive models on the use of the Collaborative Wall in the Geometric Representation Systems course and (3) analyze the students' perception about the use of the Collaborative Wall.

\section{Participants}

The sample is made up of 46 students (10 men and 36 women) who took the Geometric Representation Systems course at the National Autonomous University of Mexico (UNAM) during the 2019 school year. The average age of the participants is 18.89 years.

\section{Procedure}

The teacher of the Geometric Representation Systems course took the "Classroom of the Future 2019" Diploma in order to improve the teaching-learning conditions through pedagogy and technology. This diploma offers the use of the Collaborative Wall to promote the active role of students during the learning process. The Collaborative Wall is a web application that facilitates the organization and dissemination of ideas through the use of images and text (See Figure 1).

In the Geometric Representation Systems course, the students searched for and selected the images about Spirals in Nature (fossils, plants and animals) before the face-to-face sessions. The use of technology in the classroom was carried out during 3 sessions (Total hours: 6 ). In the face-to-face sessions, the students of the Bachelor of Visual Arts formed teams (3 students) and used the SketchUp application to manipulate the images about Spirals in Nature. Subsequently, the students used mobile devices to share and discuss the results of the school activity in the Collaborative Wall.

The research hypotheses on the use of the Collaborative Wall in the educational field are:

- Hypothesis 1 (H1): The organization of ideas in the Collaborative Wall positively influences the participation of the students 
Table 1. Questionnaire about the use of Collaborative Wall

\begin{tabular}{|c|c|c|c|c|c|c|}
\hline No. & Variable & Dimension & Question & Answer & $\mathrm{n}$ & $\%$ \\
\hline \multirow[t]{11}{*}{1} & Profile of the & Sex & 1. Indicate your sex & & & \\
\hline & students & & & Man & 10 & $21.74 \%$ \\
\hline & & & & Woman & 36 & $78.26 \%$ \\
\hline & & Age & 2. Indicate your age & & & \\
\hline & & & & 17 years & 4 & $8.70 \%$ \\
\hline & & & & 18 years & 21 & $45.65 \%$ \\
\hline & & & & 19 years & 10 & $21.74 \%$ \\
\hline & & & & 20 years & 4 & $8.70 \%$ \\
\hline & & & & 21 years & 2 & $4.35 \%$ \\
\hline & & & & 22 years & 4 & $8.70 \%$ \\
\hline & & & & 23 years & 1 & $2.17 \%$ \\
\hline \multirow[t]{19}{*}{2} & Collaborative Wall & $\begin{array}{l}\text { Organization of } \\
\text { ideas }\end{array}$ & $\begin{array}{l}\text { 3. The Collaborative Wall } \\
\text { facilitates the organization of }\end{array}$ & Too much (1) & 20 & $43.48 \%$ \\
\hline & & & ideas & Much (2) & 15 & $32.61 \%$ \\
\hline & & & & Little (3) & 7 & $15.22 \%$ \\
\hline & & & & Too little (4) & 4 & $8.70 \%$ \\
\hline & & Participation of & 4. The use of the Collaborative & & & \\
\hline & & the students & Wall improves the participation & Too much (1) & 31 & $67.39 \%$ \\
\hline & & & of the students & Much (2) & 6 & $13.04 \%$ \\
\hline & & & & Little (3) & 4 & $8.70 \%$ \\
\hline & & & & Too little (4) & 5 & $10.87 \%$ \\
\hline & & Motivation of the & 5. The use of the Collaborative & & & \\
\hline & & students & Wall increases the motivation of & Too much (1) & 24 & $52.17 \%$ \\
\hline & & & the students & Much (2) & 11 & $23.91 \%$ \\
\hline & & & & Little (3) & 4 & $8.70 \%$ \\
\hline & & & & Too little (4) & 7 & $15.22 \%$ \\
\hline & & Learning process & 6. The use of the Collaborative & & & \\
\hline & & & Wall improves the learning & Too much (1) & 18 & $39.13 \%$ \\
\hline & & & process & Much (2) & 13 & $28.26 \%$ \\
\hline & & & & Little (3) & 9 & $19.57 \%$ \\
\hline & & & & Too little (4) & 6 & $13.04 \%$ \\
\hline
\end{tabular}

- Hypothesis $2(\mathrm{H} 2)$ : The organization of ideas in the Collaborative Wall positively influences the motivation of the students

- Hypothesis $3(\mathrm{H} 3)$ : The organization of ideas in the Collaborative Wall positively influences the learning process

The predictive models on the use of the Collaborative Wall in the Geometric Representation Systems course are:

- Predictive Model 1 (PM1) on the organization of ideas in the Collaborative Wall and participation of the students

- Predictive Model 2 (PM2) on the organization of ideas in the Collaborative Wall and motivation of the students

- Predictive Model 3 (PM3) on the organization of ideas in the Collaborative Wall and learning process

\section{Data Collection}

Table 1 shows the questionnaire about the use of the Collaborative Wall in the Geometric Representation Systems course. Data collection was carried out at the National Autonomous University of Mexico (Faculty of Arts and Design) during the 2019 school year.

\section{Data Analysis}

This mixed research uses the Word Cloud app during the qualitative approach and the Rapidminer tool during the quantitative approach in order to calculate machine learning and data science. Machine learning allows 
Table 2. Results of machine learning

\begin{tabular}{|c|c|c|c|c|c|c|}
\hline Hypothesis & Training & Linear regression & Conclusion & Squared error & t-Stat & p-Value \\
\hline H1: Organization of ideas in the & $50 \%$ & $y=0.124 x+1.000$ & Accepted: 0.124 & 1.994 & 0.842 & 0.408 \\
\hline Collaborative Wall $\rightarrow$ & $60 \%$ & $y=0.208 x+0.941$ & Accepted: 0.208 & 1.945 & 1.360 & 0.185 \\
\hline participation of the students & $70 \%$ & $y=0.218 x+0.898$ & Accepted: 0.218 & 2.519 & 1.677 & 0.103 \\
\hline $\mathrm{H}$ 2: Organization of ideas in the & $50 \%$ & $y=0.337 x+1.283$ & Accepted: 0.337 & 0.778 & 1.195 & 0.245 \\
\hline Collaborative Wall $\rightarrow$ & $60 \%$ & $y=0.292 x+1.360$ & Accepted: 0.292 & 0.708 & 2.366 & 0.025 \\
\hline motivation of the students & $70 \%$ & $y=0.343 x+1.179$ & Accepted: 0.343 & 0.683 & 3.347 & 0.002 \\
\hline H3: Organization of ideas in the & $50 \%$ & $y=0.405 x+1.207$ & Accepted: 0.405 & 0.819 & 2.644 & 0.015 \\
\hline Collaborative Wall $\rightarrow$ learning & $60 \%$ & $y=0.489 x+1.072$ & Accepted: 0.489 & 0.929 & 2.872 & 0.008 \\
\hline process & $70 \%$ & $y=0.531 x+0.914$ & Accepted: 0.531 & 1.101 & 3.310 & 0.002 \\
\hline
\end{tabular}

Table 3. Conditions of the PM1

\begin{tabular}{lllll}
\hline No. & Collaborative Wall $\rightarrow$ organization of ideas & Sex & Age & Use of the Collaborative Wall $\rightarrow$ participation \\
\hline 1 & Too much & - & - & Too much \\
2 & Much & - & $>19.5$ years & Much \\
3 & Much & - & $\leq 19.5$ years & Too much \\
4 & Little & Man & - & Too little \\
5 & Little & Woman & - & Too much \\
6 & Too little & Man & $>18.5$ years & Much \\
7 & Too little & Woman & $>18.5$ years & Too little \\
8 & Too little & - & $\leq 18.5$ years & Too much \\
\hline
\end{tabular}

evaluating the research hypotheses about the use of the Collaborative Wall through the training section ( $50 \%, 60 \%$ and $70 \%$ of the sample). On the other hand, the evaluation section $(50 \%, 40 \%$ and $30 \%$ of the sample) allows identifying the accuracy of the linear regressions. Likewise, data science allows building the predictive models on the use of the Collaborative Wall in the educational field through the decision tree technique.

\section{RESULTS}

The Collaborative Wall facilitates too much $(n=20,43.48 \%)$, much $(n=15,32.61 \%)$, little $(n=7,15.22 \%)$ and too little $(n=4,8.70 \%)$ the organization of ideas (See Table 1). The results of machine learning indicate that the organization of ideas in the Collaborative Wall positively influences the participation of the students, motivation and learning process (See Table 2).

According to the results of machine learning with $50 \%(0.405), 60 \%(0.489)$ and $70 \%(0.531)$ of training, the variable that most influences the organization of ideas in the Collaborative Wall is the learning process.

\section{Participation of the Students}

The use of the Collaborative Wall improves too much $(n=31,67.39 \%)$, much $(n=6,13.04 \%)$, little $(n=4$, $8.70 \%)$ and too little $(n=5,10.87 \%)$ the participation of the students (See Table 1$)$. The results of machine learning with $50 \%(0.124), 60 \%(0.208)$ and $70 \%(0.218)$ of training indicate that $\mathrm{H} 1$ is accepted (See Table 2). Therefore, the organization of ideas in the Collaborative Wall positively influences the participation of the students.

Table 3 shows the PM1 on the use of the Collaborative Wall. For example, if the student thinks that the Collaborative Wall facilitates much the organization of ideas and has an age $>19.5$ years then the use of the Collaborative Wall improves much the participation of the students.

Also, Table 3 shows the 8 conditions of the PM1 with the accuracy of $78.26 \%$. For example, if the student thinks that the Collaborative Wall facilitates too much the organization of ideas then the use of the Collaborative Wall improves too much the participation of the students.

\section{Motivation of the Students}

The use of the Collaborative Wall increases too much $(n=24,52.17 \%)$, much ( $n=11,23.91 \%)$, little ( $n=4$, $8.70 \%)$ and too little $(n=7,15.22 \%)$ the motivation of the students (See Table 1$)$. The results of machine 
Table 4. Conditions of the PM2

\begin{tabular}{lllll}
\hline No. & Collaborative Wall $\rightarrow$ organization of ideas & Sex & Age & Use of the Collaborative Wall $\rightarrow$ motivation \\
\hline 1 & Too much & - & $>17.5$ years & Too much \\
2 & Too much & Man & $\leq 17.5$ years & Too little \\
3 & Too much & Woman & $\leq 17.5$ years & Much \\
4 & Much & - & $>19.5$ years & Much \\
5 & Much & Man & $\leq 19.5$ years & Too little \\
6 & Much & Woman & $\leq 19.5$ years & Much \\
7 & Little & Man & - & Little \\
8 & Little & Woman & $>19.5$ years & Too little \\
9 & Little & Woman & $\leq 19.5$ years & Much \\
10 & Too little & - & $>18.5$ years & Too little \\
11 & Too little & - & $\leq 18.5$ years & Too much \\
\hline
\end{tabular}

Table 5. Conditions of the PM3

\begin{tabular}{lllll}
\hline No. & Collaborative Wall $\rightarrow$ organization of ideas & Sex & Age & Use of the Collaborative Wall $\rightarrow$ learning process \\
\hline 1 & Too much & - & $>20$ years & Too little \\
2 & Too much & - & $>17.5$ and $\leq 20$ & Too much \\
& & & years & \\
3 & Too much & - & $\leq 17.5$ years & Much \\
4 & Much & - & $>17.5$ years & Much \\
5 & Much & - & $\leq 17.5$ years & Too much \\
6 & Little & Man & $>19.5$ years & Little \\
7 & Little & Woman & $>19.5$ years & Too little \\
8 & Little & - & $\leq 19.5$ and $>$ & Much \\
& & & 18.5 years & \\
9 & Little & - & $\leq 18.5$ years & Little \\
10 & Too little & - & $\leq 18.5$ years & Much \\
11 & Too little & - & $>18.5$ years & Too little \\
\hline
\end{tabular}

learning with $50 \%(0.337), 60 \%(0.292)$ and $70 \%(0.343)$ of training indicate that $\mathrm{H} 2$ is accepted (See Table 2). Therefore, the organization of ideas in the Collaborative Wall positively influences the motivation of the students.

Table 4 shows the PM2 on the use of the collaborative wall. For example, if the student thinks that the Collaborative Wall facilitates much the organization of ideas and has an age $>19.5$ years then the use of the Collaborative Wall increases much the motivation of the students.

Also, Table 4 shows the 11 conditions of PM 2 with an accuracy of $71.74 \%$. For example, if the student thinks that the Collaborative Wall facilitates too much the organization of ideas and has an age $>17.5$ years then the use of the Collaborative Wall increases too much the motivation of the students.

\section{Learning Process}

The use of the Collaborative Wall improves too much $(n=18,39.13 \%)$, much $(n=13,28.26 \%)$, little ( $n=9$, $19.57 \%)$ and too little $(n=6,13.04 \%)$ the learning process (See Table 1$)$. The results of machine learning with $50 \%(0.405), 60 \%(0.489)$ and $70 \%$ (0.531) of training indicate that H3 is accepted (See Table 2). Therefore, the organization of ideas in the Collaborative Wall positively influences the learning process.

Table 5 shows the PM3 about the use of the Collaborative Wall. For example, if the student thinks that the Collaborative Wall facilitates much the organization of ideas and has an age $>17.5$ years then the use of the Collaborative Wall improves much the learning process.

Also, Table 5 shows the 11 conditions of the PM3 with the accuracy of $71.64 \%$. For example, if the student thinks that the Collaborative Wall facilitates much the organization of ideas and has an age $\leq 17.5$ years then the use of the Collaborative Wall improves too much the learning process. 


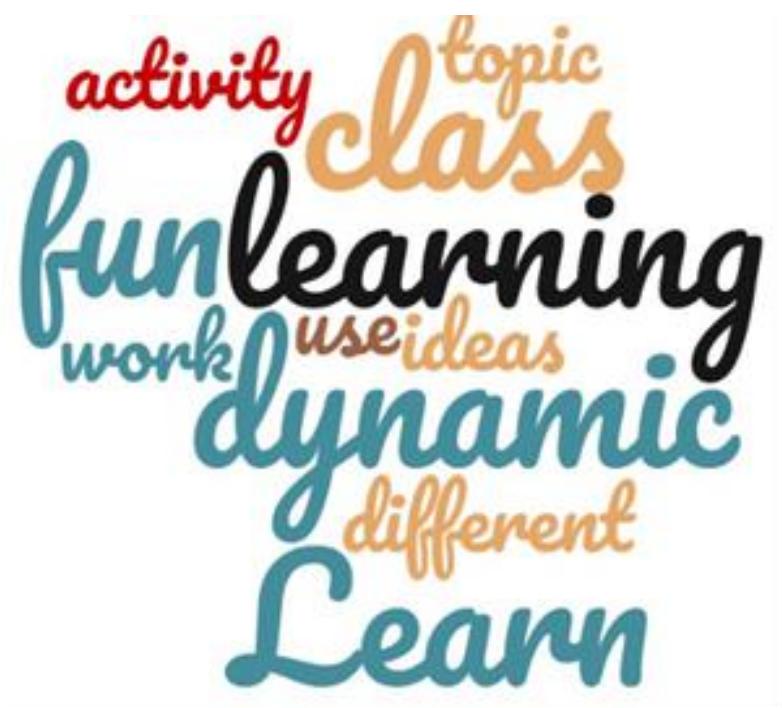

Figure 2. Word cloud about the use of the Collaborative Wall

\section{Perception of the Students}

The use of the Collaborative Wall in the Geometric Representation Systems course improved the teachinglearning conditions. In fact, this web application allows the construction of new educational spaces:

\footnotetext{
"It makes the class more entertaining" (Student 4, woman, 20 years).

"It facilitates the work in the classroom" (Student 10, woman, 18 years).
}

In the Bachelor of Visual Arts, the students mention that the use of the Collaborative Wall facilitates the learning process in the classroom through the comparison and discussion of information.

"Compare the ideas to reach a conclusion" (Student 8, woman, 18 years).

"Compare the ideas and points of view" (Student 28, man, 18 years).

Technological advances allow the creation of the school activities that favor the learning process. According to the students, the use of the Collaborative Wall in the classroom was interesting and fun.

"It is very interesting and fun. I like" (Student 32, woman, 18 years).

"We reached agreements as teams, it was fun and useful" (Student 39, man, 22 years).

Technology facilitates the organization and realization of student-centered activities. In particular, the incorporation of the Collaborative Wall in the school activities allows the active participation of students.

\footnotetext{
"We collaborate in real time" (Student 5, man, 18 years).

"Team participation" (Student 9, woman, 17 years).
}

On the other hand, the word cloud about the use of the Collaborative Wall indicates that fun, learning, class, ideas, topic, dynamic and learn are the words that have the highest frequency (See Figure 2).

\section{DISCUSSION}

The incorporation of technology in the school activities allows improving the teaching-learning conditions. In particular, most of the students ( $n=20,43.48 \%$ ) think that the Collaborative Wall facilitates too much the organization of ideas. 


\section{Participation of the Students}

Most of the students ( $n=31,67.39 \%$ ) think that the use of the Collaborative Wall improves too much the participation of the students. The results of machine learning on $\mathrm{H} 1$ are greater than 0.120 , therefore, the organization of ideas in the Collaborative Wall positively influences the participation of students. On the other hand, data science identifies 8 conditions of the PM1 with an accuracy of $78.26 \%$.

\section{Motivation of the Students}

Most of the students ( $n=24,52.17 \%$ ) think that the use of the Collaborative Wall increases too much the motivation of the students. The results of machine learning on $\mathrm{H} 2$ are greater than 0.290 , therefore, the organization of ideas in the Collaborative Wall positively influences the motivation of students. On the other hand, data science identifies 11 conditions of the PM2 with an accuracy of $71.74 \%$.

\section{Learning Process}

Most of the students ( $n=18,39.13 \%$ ) think that the use of the Collaborative Wall improves too much the learning process. The results of machine learning on $\mathrm{H} 3$ are greater than 0.400 , therefore, the organization of ideas in the Collaborative Wall positively influences the learning process. On the other hand, data science identifies 11 conditions of the PM3 with an accuracy of $71.64 \%$.

\section{Perception of the Students}

The incorporation of the Collaborative Wall in the Geometric Representation Systems course improved the teaching-learning conditions and allowed the construction of new educational spaces. In particular, this web application facilitated the comparison and discussion of information in the classroom. According to the students, the use of the Collaborative Wall in the classroom was interesting and fun. Also, this web application allows the active role of the participants during the learning process.

\section{CONCLUSION}

The incorporation of technology in the school activities is causing the realization of creative school activities. In particular, the Collaborative Wall transformed the roles of the participants during the educational process and facilitated the active role of the students in the Geometric Representation Systems course. The results of machine learning indicate that the organization of ideas in the Collaborative Wall positively influences the participation of the students, motivation and learning process. Also, data science identifies 3 predictive models of the use of this web application in the educational field.

The limitations of this research are the use of the Collaborative Wall in the Bachelor of Visual Arts and size of the sample. Therefore, future research can analyze the impact on the use of this web application in various degrees such as Computer Science, Marketing, Medicine and Administration.

Finally, teachers can organize and carry out creative school activities through the Collaborative Wall. In fact, this web application allows the construction of new educational spaces where the student has the main role during the learning process.

\section{ACKNOWLEDGEMENTS}

The participation of the following academics is appreciated: PhD Clara Alvarado Zamorano, PhD Gustavo De la Cruz Martínez, Master Ricardo Castañeda Martínez and Master Antonio M. Garcés Madrigal. Likewise, the support provided by the Faculty of Arts and Design is appreciated. 


\section{REFERENCES}

Brown, K., \& Fridman, I. (2020). Transforming Feedback: An Application Framework for Group Feedback Videos in Design. International Journal of Art \& Design Education, 39, 139-152. https://doi.org/10.1111/jade.12230

Chen, J., Zhou, J.,Wang, Y., Qi, G., Xia, C., Mo, G., \& Zhang, Z. (2020). Blended learning in basic medical laboratory courses improves medical students' abilities in self-learning, understanding, and problem solving. Advances in Physiology Education, 44(1), 9-14. https://doi.org/10.1152/advan.00076.2019

Costantino, T. (2018). STEAM by another name: Transdisciplinary practice in art and design education. Arts Education Policy Review, 119(2), 100-106. https://doi.org/10.1080/10632913.2017.1292973

Gonzalez, A. A., Lizana, P. A., Pino, S., Miller, B. G., \& Merino, C. (2020). Augmented reality-based learning for the comprehension of cardiac physiology in undergraduate biomedical students. Advances in Physiology Education, 44(3), 314-322. https://doi.org/10.1152/advan.00137.2019

Gopalan, C., Fentem, A., \& Rever, A. L. (2020). The refinement of flipped teaching implementation to include retrieval practice. Advances in Physiology Education, 44(2), 131-137. https://doi.org/10.1152/advan.00143.2019

Kerr, J., \& Lawson, G. (2020). Augmented Reality in Design Education: Landscape Architecture Studies as AR Experience. International Journal of Art \& Design Education, 39, 6-21. https://doi.org/10.1111/jade.12227

Kite, J., Schlub, T. E., Zhang, Y., Choi, S., Craske, S., \& Dickson, M. (2020). Exploring lecturer and student perceptions and use of a learning management system in a postgraduate public health environment. E-Learning and Digital Media, 17(3), 183-198. https://doi.org/10.1177/2042753020909217

Mannathoko, M. C., \& Mamvuto, A. (2018). Learner involvement in art and design education assessment: The missing matrix in Botswana's primary schools. Arts Education Policy Review, 119(3), 172-184. https://doi.org/10.1080/10632913.2016.1260081

Marshalsey, L., \& Sclater, M. (2019). Arts-Based Educational Research: The Challenges of Social Media and Video-Based Research Methods in Communication Design Education. International Journal of Art \& Design Education, 38, 723-739. https://doi.org/10.1111/jade.12252

Pavlou, V. (2020). Art Technology Integration: Digital Storytellying as a Transformative Pedagogy in Primary Education. International Journal of Art \& Design Education, 39, 195-210. https://doi.org/10.1111/jade.12254

Rathner, J. A., \& Schier, M. A. (2020). The impact of flipped classroom andragogy on student assessment performance and perception of learning experience in two advanced physiology subjects. Advances in Physiology Education, 44(1), 80-92. https://doi.org/10.1152/advan.00125.2019

Salas-Rueda, R. A. (2020). Impact of the WampServer application in Blended learning considering data science, machine learning, and neural networks. E-Learning and Digital Media, 17(3), 199-217. https://doi.org/10.1177/2042753020901730

Salas-Rueda, R. A., Salas-Rueda, E. P., \& Salas-Rueda, R. D. (2020). Analysis and design of the web game on descriptive statistics through the ADDIE model, data science and machine learning. International Journal of Education in Mathematics, Science and Technology, 8(3), 245-260. https://doi.org/10.46328/ijemst.v8i3.759

Souleles, N., Savva, S., Watters, H. \& Annesley, A. (2017). Perceptions of art and design faculty on the instructional value of iPads. Technology, Pedagogy and Education, 26(2), 211-223. https://doi.org/10.1080/1475939X.2016.1199390 
Strycker, J. (2020). K-12 art teacher technology use and preparation. Heliyon, 6(7), 1-12. https://doi.org/10.1016/j.heliyon.2020.e04358

Tadayonifar, M., \& Entezari, M. (2020). Does flipped learning affect language skills and learning styles differently? E-Learning and Digital Media, 17(4), 324-340. https://doi.org/10.1177/2042753020931776

Wargo, J. M. (2020). Sounding out synthesis: Investigating how educators in a teaching with technology course use sonic composition to remix reflection. E-Learning and Digital Media, 17(3), 218-235. https://doi.org/10.1177/2042753020902784

Wet, A. J. (2017). An educational tool to encourage higher level thinking skills in the selection of images for fashion design mood boards: an action research approach. International Journal of Fashion Design, Technology and Education, 10(1), 16-25. https://doi.org/10.1080/17543266.2016.1173236

Wilks, J., Cutcher, A., \& Wilks, S. (2015). Digital Technology in the Visual Arts Classroom: An [Un]Easy Partnership. Studies in Art Education, 54(1), 54-65. https://doi.org/10.1080/00393541.2012.11518879

Correspondence: Ricardo-Adán Salas-Rueda, Institute of Applied Sciences and Technology, National Autonomous University of Mexico, Mexico. E-mail: ricardo.salas@icat.unam.mx 